\title{
Discrimination of quarry blasts and microearth- quakes using adaptive neuro-fuzzy inference systems in the Tehran region
}

\author{
Institute of Geophysics, Tehran University, Tehran, Iran. E-mail :j_farahani@ut.ac.ir
}

(Received October 8, 2014: Revised accepted June 20 ${ }^{\text {th }}$, 2015)

The purpose of this research is to demonstrate the use of Adaptive Neuro-Fuzzy Inference System (ANFIS) for discrimination between quarry blasts and microearthquakes in the Tehran region using data from the Broadband Iranian National Network Center (BIN). In the south and southeast of Tehran, a large number of quarry blasts "contaminate" the earthquake catalog. In order to identify the real seismicity (tectonic earthquakes) in the region, we need to discriminate quarry blasts from natural earthquakes in the catalog. ANFIS classifiers were used for identifying and categorizing the two kinds of seismic events. Neuro-fuzzy coding was applied using six features as ANFIS inputs. We investigated waveforms of 506 seismic events $(0.9<M L<4.2)$ from the BIN network and determined differences between earthquakes and quarry blasts based on input features. These features include the original time of event, distance (source to station), latitude of epicenter, longitude of epicenter, magnitude, and two features for spectral analysis of their seismograms. The results of this study indicate that, out of a total of 506 seismic records, the neuro-fuzzy ANFIS approach identified $24.5 \%$ (124 events) and $75.5 \%$ (386 events) were quarry blasts and natural earthquakes, respectively. Our revised earthquake catalog provides improved data for realistic earthquake hazard assessment. Moreover, active faults will be detected correctly.

\section{Introduction}

In the framework of verification of Comprehensive Nuclear Test Ban Treaty (CTBT), discrimination of earthquakes and man-made events such as blasting events are very important scientific topic (Walter and Hartse, 2013). One of the major concerns of the CTBT is a special interest for identification of the numerous low-yield mining events. Based on the treaty, a global verification system including a network of 321 monitoring stations is distributed in worldwide. Walter and Hartse in 2013 believed that discrimination between small magnitude banned nuclear tests, background of earthquakes and seismic events related to mining is a challenging research problem.

During the past few years, the application of soft computing and machine learning approaches has played an increasingly important role in different sciences, especially in the interpretation, pattern recognition and data analysis. Fuzzy systems with adaptation and learning capabilities are one of the successful methods. The objective of our study was to use ANFIS (Adaptive Neuro Fuzzy Inference System) as a classifier for detection of seismic events. Some researchers have used neural networks for determination of regional seismic events (Dysart and Pulli, 1990; Dowla et al., 1990; Joswig, 1995; Wang and Teng, 1995; Musil and Plesinger, 1996; Tiira, 1996; Lee and Oh, 1996; Gitterman et al., 1998; Tiira, 1999; Ursino et al., 2001; Jenkins and Sereno, 2001; Del Pezzo et al., 2003; Scarpetta et al., 2005; Yildirim and Horasan, 2008). In addition, a number of researchers have used fuzzy methods (Muller et al., 1999; Yildirim et al., 2011; Vasheghani-Farahani et al., 2012). Moreover, one of the most recent researches into seismic events (Ait Laasri et al., 2015) used a fuzzy expert system for automatic seismic signal classification. In the present study, the classification of seismic events was done by the ANFIS method, and for more accurate classification, feature selection was used. We used forward selection as the purpose of classification between quarry blasts and micro-earthquakes. Feature selection algorithms improve the methods of feasibility classification. We used six features for recognizing and categorizing the seismic events. An important advantage of neuro-fuzzy modelling is considered to be the use of neural networks together with fuzzy logic models. Neural networks provide learning capacity and ability for generalization while fuzzy logic provides logical reasoning based on inference rules. Therefore, it is beneficial to use this approach where data is produced by different sources (Corona-Nakamura et al., 2008). Moreover, other advantages are that it is rapid, easy to operate, and inexpensive (Boyacioglu and Avci, 2010).

\section{Seismotectonic setting}

Iran is located in Alpine-Himalayan seismic belt; and Tehran, its capital, is situated in the Alborz and central Iranian tectonic zones, surrounded by several active faults (Tchalenko et al., 1974). Tehran has experienced some destructive earthquakes in the past. The present morphotectonic structure of the zone was defined by several effective orogenic events. The geological structures have general trends to the 
NW-SE of the western part of the zone. The trend shifts towards the $\mathrm{NE}$ in the eastern portion of the zone. Two important faults located in south of Tehran are the Eyvanekey fault (75-80 km in length) with a compressive mechanism and strike slip component, and the Kahrizak fault (40 km in length) with a compressive mechanism (VasheghaniFarahani and Zaré, 2011). There are some active mines in south and southeast of Tehran. These produce many small explosions; therefore, they cause data contamination for most seismicity studies in this region.

\section{Objectives}

The aim of this research is to methodically examine, analyze and categorize seismic events caused both naturally and by explosions recorded by the broad band network in Tehran region using the ANFIS method. It was found that this method could be applied successfully by the permanent local seismological network of the Tehran Disaster Mitigation and Management Organization (Vasheghani-Farahani et al., 2012). One of the important aspects of this study is the attention paid to quantitatively identifying the differences between earthquakes and explosions in terms of their spectral content. Our main motivation for this research was to create a separate catalog for broadband waves from natural earthquakes, with no quarry blast data, for the Tehran region. Moreover, we can identify active faults through the BIN Network without any data contamination from quarry blasts. Thus, seismic hazard assessment by earthquake independent catalogs will boost confidence in disaster risk and hazards research, because the results of natural hazard and risk studies will be realistic. Therefore, our studies will help the society to reduce the risks from natural hazards and improve a set of sustainable development goals and seismic safety for future precautionary programs in the country.

\section{Data}

The dataset for this study consists of 506 seismic events from 2004 to 2010 in the magnitude range of $0.9<\mathrm{ML}<4.2$ recorded in Tehran region by the permanent Broadband Iranian National Network Center (BIN) using Guralp CMG-3TD instruments. We used SEISAN analysis software for the epicenter location (Havskov and Ottemoller, 2005) and represented each seismic event by a set of six features including the time, distance, latitude, and longitude of its epicenter as well as magnitude and the spectral analysis of their seismograms. The waveform was removed when the signal was very noisy. A signal was eliminated if the signal-to-noise ratio was less than two. Figure 1 shows the distribution of the seismic events from 2004 to 2010. Table 1 lists the station names and coordinates for BIN Network. These stations recorded data in average bandwidth $0.01 \mathrm{~Hz}$ until $50 \mathrm{~Hz}$ in continuous mode at 50 samples per second.

\section{Theory of ANFIS}

In this section, we present the ANFIS Architecture. Jang in 1992 and 1993 believed that ANFIS is a fuzzy Sugeno model (1986) of an adaptive system framework and can make easy learning and adaptation. We suppose two inputs, $x$ and $y$, and an output, $z$, for the fuzzy inference system under consideration. The fuzzy rule of the first-order Sugeno set with two fuzzy "if-then" rules has this form: where $\mathrm{x}$ and $\mathrm{y}$ are the inputs; $\mathrm{Ai}$ and Bi are the fuzzy sets; fi is the output within the fuzzy region specified by the fuzzy rule; and pi, qi,

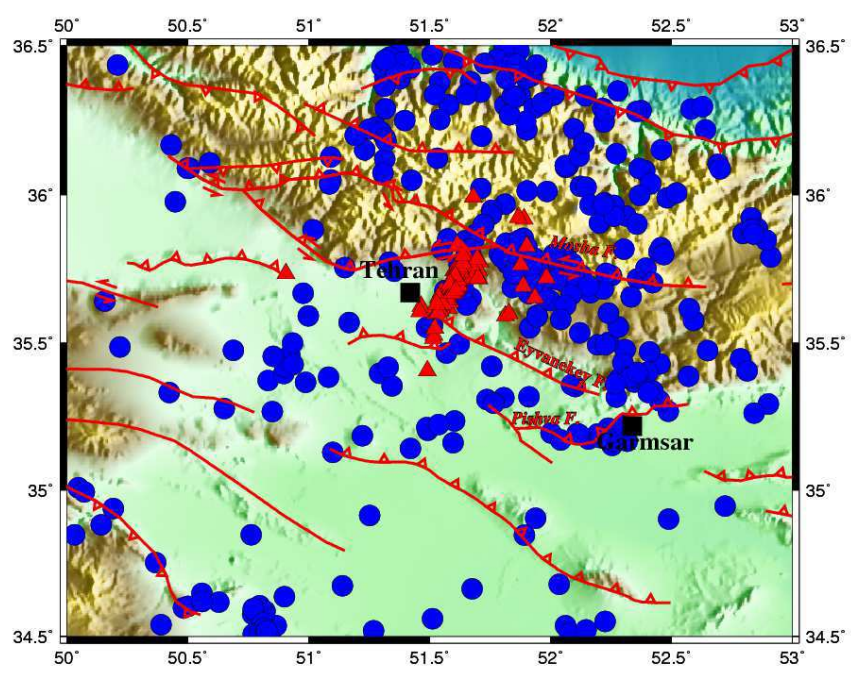

Figure 1. Distribution of the seismic events (2004-2010), (•) for microearthquakes and $(\mathbf{\Delta})$ for quarry blasts.

and ri are the design parameters determined during the training process.

Figure. 2(a) demonstrates the fuzzy reasoning mechanism for a first-order Sugeno fuzzy model, and ANFIS architecture for implementing these two rules is shown in Fig. 2(b).

In layer 1, every node is an adaptive node. The outputs of the first layer are fuzzy membership inputs given by:

$$
\begin{array}{ll}
O_{i}^{1}=\mu A_{i}(x), & \text { for } i=1,2 \\
O_{i}^{1}=\mu B_{i}(x), & \text { for } i=3,4
\end{array}
$$

$A_{i}(x), \mu B_{i-2}(y)$ can adopt any fuzzy membership function such as the generalized bell function, the Gaussian function, etc. For instance,

Table 1. Station coordinates

\begin{tabular}{lccc}
\hline Station & $\begin{array}{c}\text { Lat. N } \\
(\text { degree })\end{array}$ & $\begin{array}{c}\text { Long. E } \\
(\text { degree })\end{array}$ & $\begin{array}{c}\text { Elevation } \\
(\mathrm{m})\end{array}$ \\
\hline Tehran (THKV) & 35.916 & 50.879 & 1795 \\
Ashtian (ASAO) & 34.548 & 50.025 & 2217 \\
Tehran (CHTH) & 35.908 & 51.126 & 2350 \\
Damavand (DAMV) & 35.630 & 51.971 & 2520 \\
Ghom (GHVR) & 34.480 & 51.295 & 927 \\
Persian Gulf (BNDS) & 27.399 & 56.171 & 1500 \\
Bojnurd (BJRD) & 37.700 & 57.408 & 1337 \\
Germi-Ardebil (GRMI) & 38.810 & 47.894 & 1300 \\
Ghir-Karzin (GHIR) & 28.286 & 52.987 & 1200 \\
Ghom (GHVR) & 34.480 & 51.295 & 927 \\
Kerman (KRBR) & 29.982 & 56.761 & 2576 \\
Khomeyn (KHMZ) & 33.739 & 49.959 & 1985 \\
Maku (MAKU) & 39.355 & 44.683 & 1730 \\
Maravetape (MRVT) & 37.659 & 56.089 & 870 \\
Naein (NASN) & 32.799 & 52.808 & 2379 \\
Ramhormoz (RMKL) & 30.982 & 49.809 & 176 \\
Sanandaj (SNGE) & 35.093 & 47.347 & 1940 \\
Shahrakht (SHRT) & 33.646 & 60.295 & 837 \\
Shahrood (SHRD) & 36 & 56.01 & 1264 \\
Shooshtar (SHGR) & 32.108 & 48.801 & 150 \\
Tabas (TABS) & 33.649 & 57.119 & \\
Zahedan (ZHSF) & 29.611 & 60.775 & 1575 \\
Zanjan (ZNJK) & 36.670 & 48.685 & 2200 \\
\hline
\end{tabular}




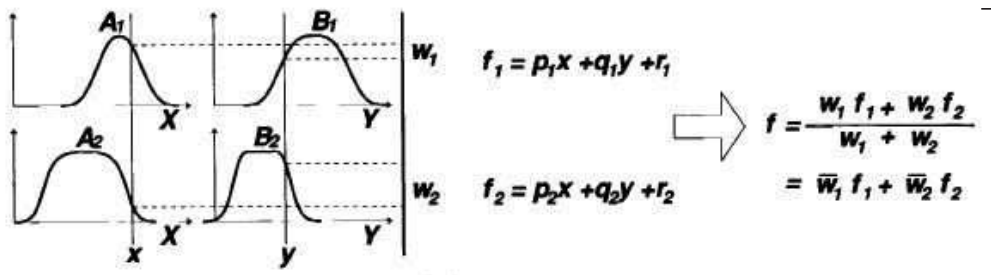

(a)

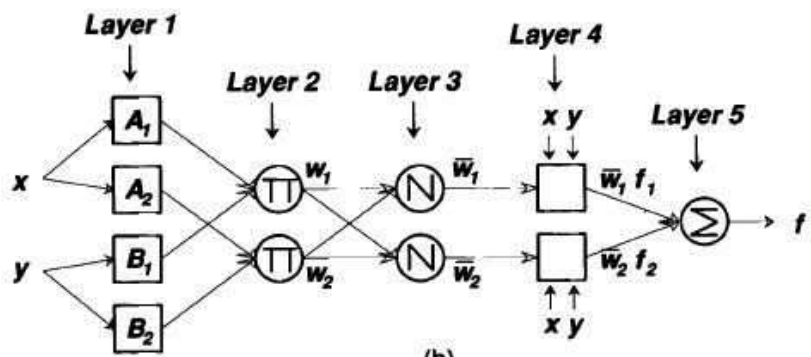

(b)

Figure 2. (a) A two inputs to a first order Sugeno fuzzy model, (b) ANFIS structure: $\mathrm{O}=$ fixed node; $\square=$ adaptive node (Jang and Sun, 1995)

if the Gaussian membership function is employed, $\mu_{A i}(x)$ is given by:

$$
\mu_{A i}(\mathrm{x})=\exp \left[-\left(\frac{x-m_{i}}{\delta_{\mathrm{i}}}\right)^{2}\right] \mathrm{i}=1,2
$$

where $\mathrm{m}_{\mathrm{i}}$ (mean value) parameters and $\delta_{\mathrm{i}}$ (premise parameters) are the parameters of the membership function (premise parameters). In layer 2, every node is a fixed node. Each node output of the second layer represents the firing strengths of the rules, which can be shown by:

$$
O_{i}^{2}=w_{i}=\mu A_{i}(x) \mu B_{i}(y), \quad \mathrm{i}=1,2
$$

Every node in the layer 3 is a fixed node labeled N. They play a normalization role to the firing strengths from the previous layer. The outputs of this layer can be represented as:

$$
O_{i}^{3}=\bar{w}_{i}=\frac{w_{i}}{w_{1}+w_{2}}, \quad \mathrm{i}=1,2
$$

The output of each node in the layer 4 is an adaptive node that is simply the product of the normalized firing strength and a first-order polynomial (for a first-order Sugeno model). Thus, the outputs of this layer are:

$$
O_{i}^{4}=\bar{w}_{i} f_{i}=\bar{w}_{i}\left(p_{i} x+q_{i} y+r_{i}\right)
$$

In layer 5, the single node performs the overall output as the summation of all incoming signals. Hence, the overall output of the model would be:

$$
\text { Overall Output }=O_{i}^{4}=\sum \bar{w}_{i} f_{i}=\frac{\sum_{i} w_{i} f_{i}}{\sum_{i} w_{i}}
$$

Therefore, we observed two adaptive layers, the first and fourth layers, in this ANFIS architecture. In layer 1, there are two modifiable parameters $\left\{\mathrm{m}_{\mathrm{i}}, \delta_{\mathrm{i}}\right\}$ related to the input membership functions that are the premise parameters. In layer 4 , there are three modifiable parameters $\left\{p_{i}, q_{i}, r_{i}\right\}$ pertaining to the first-order polynomial. These parameters are called consequent parameters (Jang 1992, 1993).

\section{Fuzzy systems}

The neuro-fuzzy system is effective in different fields such as systems control, data analysis and decision support. Moreover, it is an effective tool to deal with complicated systems. There are three types of neuro-fuzzy system as follows (Nauck, 1997; Vieira et al., 2004; Hamdan, 2013):

\section{Cooperative Neuro-Fuzzy System \\ 2 Concurrent Neuro-Fuzzy System \\ 3 Hybrid Neuro-Fuzzy System}

This study applies the third type in which the fuzzy system used a learning algorithm inspired by the neural networks to decide the parameters used during pattern processing. Jang $(1992,1993)$ believed that the hybrid algorithm was composed of a forward and a backward pass. For optimizing the consequent parameters with fixed premise parameters, the least squares procedure (forward pass) was used. Once the optimal consequent parameters were found, the backward pass started immediately. The gradient descent procedure (backward pass) was applied to optimally adjust the premise parameters corresponding to the fuzzy sets in the input domain. The output of the ANFIS was computed based on employing the consequent parameters found in the forward pass. Then, the output error was applied for adapting the premise parameters by means of a standard back-propagation algorithm. The hybrid algorithm has been demonstrated to be highly efficient in training the ANFIS (Jang 1992, 1993).

\section{ANFIS model and its application to seismic events}

The ANFIS model was used to discriminate between microearthquakes and quarry blasts. In this application, $65 \%$ of data were used to train, and the remaining $35 \%$ of the data were then used to test, the model. We selected 320 out of 2530 signals (506 events) for training and testing database to secure the desired output. Our ANFIS network was made with $65 \%$ of data for training (208 signals) and $35 \%$ of the remaining data (112 signals). After this step, the remaining 2210 data were clustered based on 320 data clusters. For the rest of data for which we did not know their target (whether they were natural earthquakes or blasts), classification of seismic events was done by several small categories as a validation with using the same structure in the ANFIS network that resulted from training data (208 signals). Therefore, we checked our classification results by an expert certification. In our ANFIS network, data normalization was done for data processing in the 0-1 range to obtain better results. We selected three membership functions and Gaussian membership functions with the maximum equal to one and minimum equal to zero. We checked the outputs of ANFIS to see whether it is near the desired output ( 1 for earthquakes and 0 for quarry blasts). We considered 50 training periods, and the final test error value obtained about $8.5 \times 10^{-4}$.

\section{Feature selection}

One of the most important issues in classification experiments is feature selection that is a process used in machine learning wherever a subdivision of the features accessible from the data is chosen for 
using a learning algorithm (Sewell, 2007). We do not often know which subset of features will lead to the best classification. The process helps us to identify the unnecessary features. Feature subset selection removes many redundant input features that could lead to over-fitting (Siva Prasad et al., 2014). Peng et al., 2005 believed that the feature selection is critical to minimize classification error. In this study, we used forward feature selection for categorization of seismic events in the Tehran region. In this method, at the outset we did not have any identified features, but we added them one by one. During this processing, we noticed some features decrease correct classification rate (CCR) and these were deleted from the input features. At each step, if adding the feature led towards minimizing the classification error, we retained the feature. Otherwise, it was redundant for our purpose. For example, our first feature was time, then we added latitude, at the next step we added magnitude etc. The CCR result for "time" was very high because quarry blasts frequently occurred during the day. Therefore, this input feature was very useful in the classification (Vasheghani-Farahani et al., 2012).

\section{Spectral characteristics}

There are significant differences between earthquake spectral and
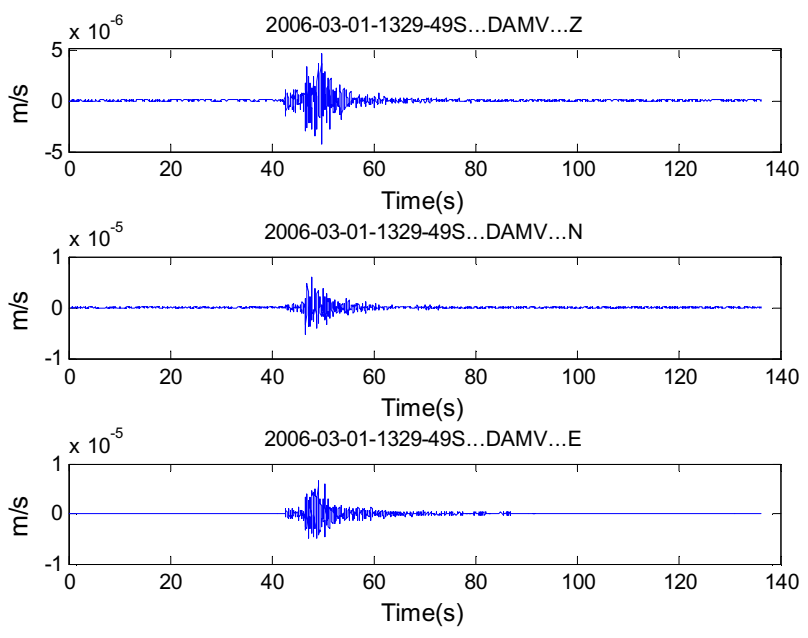

Figure 3. (a) Typical example of three component microearthquake at station DAMV with $M_{L}=2.1$ at a distance of $26.2 \mathrm{~km}$, (b) The spectrum amplitude for vertical component of microearthquake.
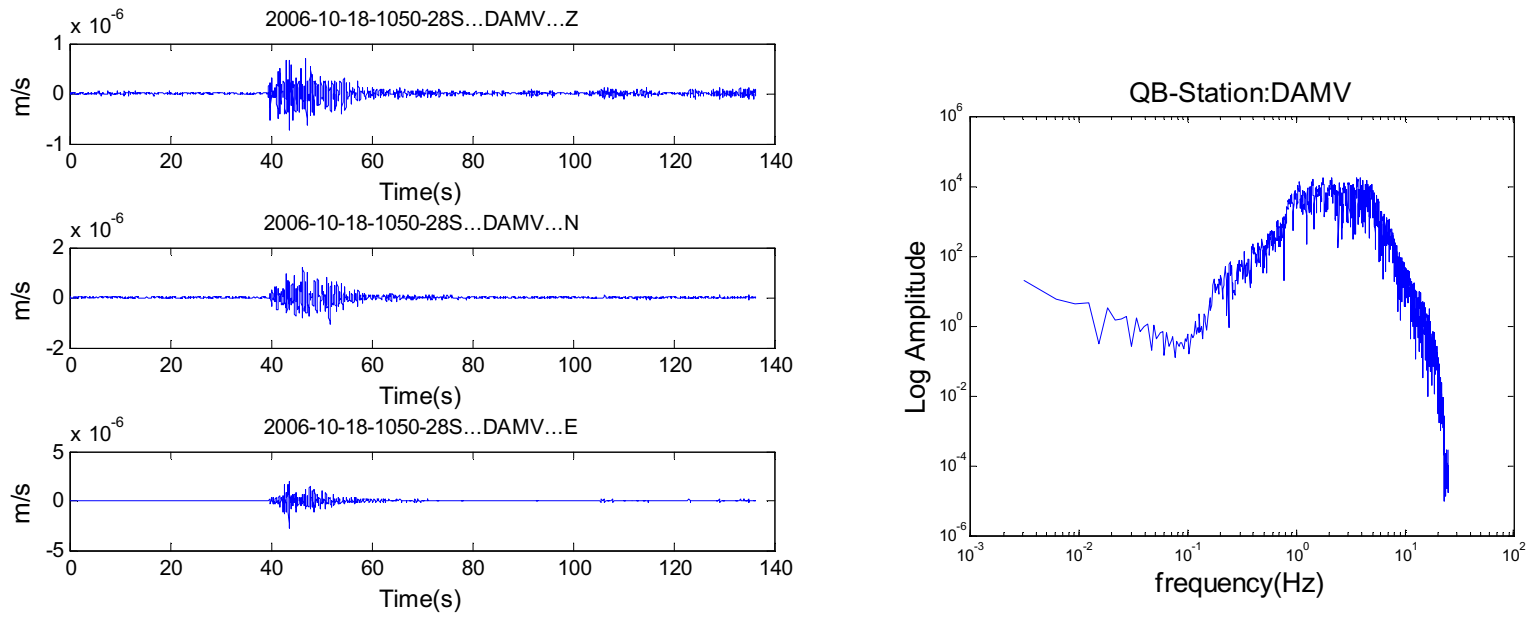

Figure 4. (a) Typical example of three component quarry blast at station DAMV with $M_{L}=1.3$ at a distance of $17.1 \mathrm{~km}$, (b) The spectrum amplitude for vertical component of quarry blast.

quarry blast spectral in the Tehran region. Vasheghani-Farahani et al., 2012 discussed their spectral features based on mean fc for displacement $\mathrm{P}_{\mathrm{g}}$ waves (vertical component) for all signals in the TDMMO network. In this study, we used mean fc for $\mathrm{P}_{\mathrm{g}}$ waves (vertical component) and amplitude spectral velocity from the BIN network. In fact, two spectral features were used in the present study. We compared the velocity spectra of microearthquakes and quarry blasts together for complete seismogram signals. Figure 3(a) and Figure 4(a) show an example of seismograms of all three components recorded at station DAMV (Damavand) for microearthquake and quarry blast, respectively, and Figures 3(b) and 4(b) show the spectrum of amplitude of vertical component. The results showed that microearthquakes contained the higher energy in velocity spectral ordinates (Vasheghani-Farahani and Zare, 2014) in frequency range of 0.5 to $10.0 \mathrm{~Hz}$. During processing of raw data, all continuous records were checked carefully. Initially, signals with high noise were removed before admission to future processing. The next step was to locate the epicenters of all events using SEISAN earthquake analysis software. We removed the instrument response in the recorded signals for spectral analysis. In order to study spectral amplitudes, we applied a band pass filtering of the data using a four-pole Butterworth band pass filter for waveforms.

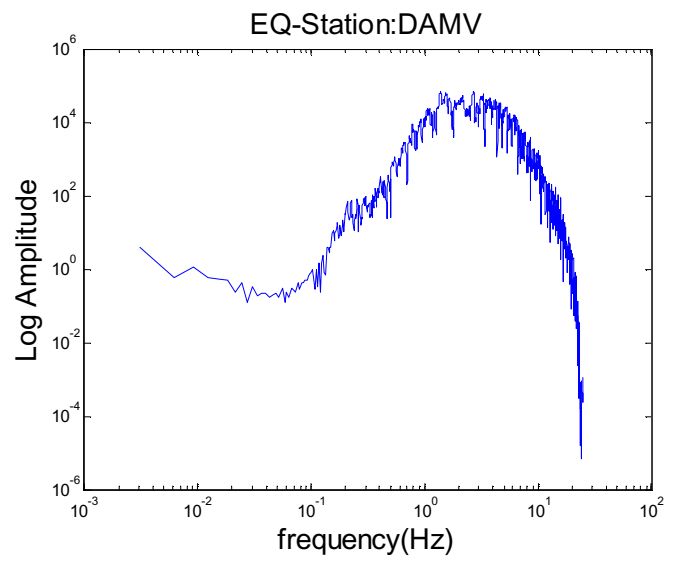


We tried to select data with effective signal to noise ratio in this study. Our criterion for signal to noise ratio for all waveforms was equal to, or greater than, 2. Therefore, the velocity spectrum of microearthquakes and quarry blasts were compared together after the data processing steps described above. Moreover, we compared $\mathrm{p}_{\mathrm{g}}{ }^{-}$ wave displacement spectra of quarry blasts and microearthquakes.

Our previous studies of the body wave showed higher attenuation for quarry blasts than natural earthquakes in the south and southeast Tehran region. The results were:

$$
\begin{aligned}
& \mathrm{Q}_{\mathrm{p}}^{-1}=(100 \pm 6) \times 10^{-3}\left(\mathrm{f}^{-1 \pm 0.07)}\right. \text { and } \\
& \mathrm{Q}_{\mathrm{s}}^{-1}=(73 \pm 2) \times 10^{-3}\left(\mathrm{f}^{-1.06 \pm 0.03)}\right. \text { (Vasheghani-Farahani et al, 2012). }
\end{aligned}
$$

As a result, the corner frequency $f_{c}$ for $p_{g}$-wave from vertical component data with high-quality signal to noise ratio could be estimated in the present study for data from the BIN network (Figure 5(a) and Figure 5(b)). According to Figures 3(b) and 4(b), the amplitude spectral velocity is different and higher for microearthquakes (about $10^{5}$ ), but about $10^{4}$ for quarry blasts. The amplitude spectral velocity from vertical component data from microearthquakes, Figure 3(b), has higher frequency content than quarry blasts.

This characteristic along with spectral corner frequency $\left(f_{c}\right)$ for events (Figure 5a and 5b) helps us to have a trustworthy analysis of seismic discriminant in Tehran region.

Based on Allmann and Shearer, 2008 and Vasheghani-Farahani et al., 2012, quarry blasts spectra usually have steeper "fall-offs" than $\omega^{-2}$ at high frequencies, leading to lower corner frequency estimates. Moreover, microearthquake spectra contain high-frequency energy compared with the spectrum of the quarry blasts (Gitterman and Shapira, 1993). Allman and Shearer, 2008 believed that shallow quarry blast data, because of the lack of high frequencies, probably reflects strong attenuation. In our data, the spectral corner frequency for $\left(\mathrm{P}_{\mathrm{g}}\right)$ and vertical component showed differences between microearhquakes and quarry blasts. Figure 5 ( $\mathrm{a}$ and $\mathrm{b}$ ) provides an example of spectral data from events recorded by the BIN network. The results for mean $\mathrm{f}_{\mathrm{c}}$ of $\mathrm{P}_{\mathrm{g}}$ waves, vertical component for microearthquakes and quarry blasts obtained in the Tehran region were 5.9 and $3.8 \mathrm{~Hz}$, respectively. The lower corner frequency for small explosions is related to higher attenuation in the shallow crust of Tehran.

\section{Simulation results}

We had 320 signals for training and testing the database, 176 of which were microearthquakes and 144 of which were blast signals. In our ANFIS model, 208 of the signals were used for training and

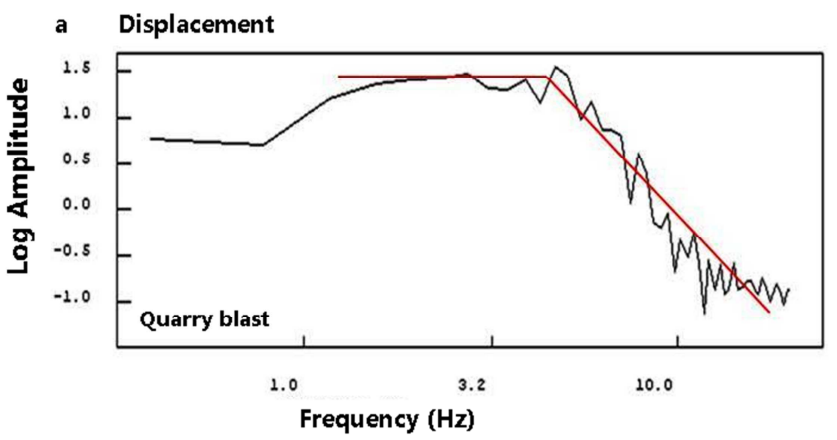

the rest for testing. Our testing data (112 signals) consisted of 53 for quarry blasts and 59 for microearthquakes. We determined the test performance of classifiers by the computation of the classifiers. Performance of classifiers was evaluated in terms of sensitivity, specificity and accuracy. The terms definition were:

Specificity: number of correct classified quarry blast records out of the total quarry blast records.

Sensitivity: number of correct classified microearthquake records out of the total microearthquake records.

Accuracy: number of correct classified records out of the total number of records.

We repeated this experience ten times, then calculated the average of the results and were able to demonstrate the classification of results from the ANFIS classifier by a confusion matrix (Table 2).

Table 2 Confusion matrix for testing

\begin{tabular}{lcc}
\hline Desired result & $\begin{array}{c}\text { Output result } \\
\text { Quarry blast } \\
\text { signals }\end{array}$ & $\begin{array}{c}\text { Microearthquake } \\
\text { signals }\end{array}$ \\
\hline Quarry blast signals & $\mathbf{5 2}$ & 1 \\
\hline Microearthquake signals & 1 & $\mathbf{5 8}$ \\
\hline
\end{tabular}

According to the confusion matrix, one quarry blast signal was classified incorrectly as microearthquake signal, and one microearthquake signal was classified as quarry blast signal. The statistical parameters for the testing data were $98.30 \%$ for sensitivity, $98.11 \%$ for specificity, and $98.21 \%$ for accuracy (Table 3).

Table 3. Statistical parameter values

\begin{tabular}{cccc}
\hline Method & Sensitivity $\%$ & Specificity $\%$ & Accuracy $\%$ \\
\hline ANFIS & 98.30 & 98.11 & 98.21 \\
\hline
\end{tabular}

Moreover, we obtained simulation results for the total of events detected by the network. There were 506 events in the seismic database. Therefore, for 2210 signals (442 events), the target of which was not available, we considered 1 for a microearthquake and 0 for a quarry blast for the desired output from the ANFIS model. The confusion matrix for the database is shown in Table 4.

Table 4. Confusion matrix for database

\begin{tabular}{lcc}
\hline Desired result & $\begin{array}{c}\text { Output result } \\
\text { Quarry blast } \\
\text { signals }\end{array}$ & $\begin{array}{c}\text { Microearthquake } \\
\text { signals }\end{array}$ \\
\hline Quarry blast signals & $\mathbf{9 4}$ & 1 \\
Microearthquake signals & 3 & $\mathbf{3 4 4}$ \\
\hline
\end{tabular}

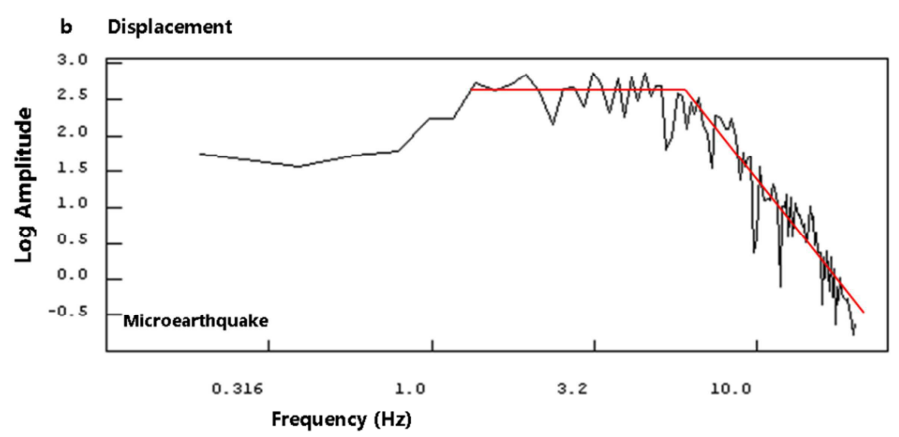

Figure 5. Displacement spectral characteristics for (a) quarry blast and (b) micro earthquake 
Table 5. Database statistical parameters

\begin{tabular}{cccc}
\hline Method & Sensitivity\% & Specificity\% & Accuracy\% \\
\hline ANFIS & 99.14 & 98.95 & 99.09 \\
\hline
\end{tabular}

According to the confusion matrix for the database, three quarry blast events were classified incorrectly as microearthquake events, and one microearthquake event was classified as quarry blast event. The statistical parameters for the database are shown in Table 5.

\section{Receiver Operating Characteristic (ROC) Curve}

Receiver Operating Characteristic (ROC) curves illustrate the performance of binary classifiers (Fawcett, 2003). ROC curve describes the inherent tradeoff between sensitivity and specificity of a diagnostic test (Du-Yih et al., 2004). Moreover, the ROC curve is defined as a plot of the 'sensitivity' ( $\mathrm{Sn}$ ) against the '1-specificity' (1-Sp):

$$
\begin{aligned}
& \mathrm{Sn}=(\mathrm{TP} / \mathrm{TP}+\mathrm{FN}) \\
& 1-\mathrm{Sp}=(\mathrm{FP} / \mathrm{TP}+\mathrm{FN})
\end{aligned}
$$

where TP is the number of true positives, TN is the number of true negatives, FP is the number of false positives, and FN is the number of false negatives. Az shows performance measure because it indicates how reliably the detection can be performed.

Generally, $\mathrm{Az}=1$ shows a perfect classification. Thus, we attained a good classification performance using this method, which yields an area under the ROC curve Az $=0.99199$ (Figure 6). After classification by ANFIS, we presented the classifications indicated in Table 6 .

\section{Conclusions}

The discrimination between quarry blasts and microearthquakes is an important matter for the verification of compliance with a



Figure 6. ROC plot.
Table 6. Description of database

\begin{tabular}{lc}
\hline Class & $\begin{array}{c}\text { Number of } \\
\text { events }\end{array}$ \\
\hline Earthquake & 382 \\
Quarry blasts & 124 \\
Total & 506 \\
\hline
\end{tabular}

Comprehensive Test Ban Treaty (Dahy and Hassib, 2009). In this study, we applied a classification system for the discrimination of seismic events in Tehran region using a neuro-fuzzy ANFIS system from 2004 to 2010 (506 events from the BIN network). ANFIS is an appropriate method for the prediction of seismic events. We applied hybrid neuro-fuzzy system (the combination of gradient descent and least squares algorithm). The hybrid approach combines the fuzzy logic qualitative approach and adaptive neural network capabilities for better performance. This hybrid learning converges much faster since it decreases the dimension of the search space of the original back-propagation method (Jang and Sun, 1995). Therefore, this method is a useful tool, because it is a rapid and easy system for prediction of seismic events. We propose that it can be considered as a good approach for classifying these events. Moreover, It should be noted that the spectral feature in ANFIS network was very effective and had a good recognition percentage in decreasing the errors in classifying the seismic events. We conclude that spectral analysis (displacement $\mathrm{P}_{\mathrm{g}}$ - wave and velocity spectrum for complete seismogram signals) indicates high reliability for discrimination of events in Tehran region.

\section{Acknowledgement}

Data were obtained from Broadband Iranian National Network Center (BIN). The author appreciates International Institute of Earthquake Engineering and Seismology for the delivery of the recorded data of Tehran region used in this study.

\section{References}

Allmann, B.P. and Shearer, P.M., 2008. Spectral discrimination between quarry blasts and earthquakes in Southern California. Bulletin of the Seismological Society of America, v. 98, pp. 2073-2079.

Ait Laasri., E.H., Akhouayri., E.S., Agliza., D. Zonta. D. and Atmani., A., 2015, A fuzzy expert system for automatic seismic signal classification. Expert Systems with Applications, v. 42 (3), pp. 1013-1027. DOI: 10.1016/j.eswa.2014.08.023.

Boyacioglu., M.A. and Avci., D., 2010, An Adaptive Network-based Fuzzy Inference System (ANFIS) for the prediction of stock market return: The case of the Istanbul stock ex-change. Expert Systems with Applications, v. 37 (12), pp. 7908-7912.

Corona-Nakamura, M.A., Ruelas, R., Ojeda-Magana, B. and Andiana, D., 2008. Classification of domestic water consumption using an Anfis model, World Automation Congress (WAC 2008), HI, USA, pp. 1-9. ISBN: 9781-889335-38-4

Dahy, A.S. and Hassib, H.G., 2009, Discriminating nuclear explosions from earthquakes at teleseismic distances, European Journal of Applied Sciences, v. 4(1), pp.47-52.

Del Pezzo, E., Esposito, A., Giudicepietro, F., Marinaro, M., Martini, M. and Scarpetta, S., 2003, Discrimination of earthquakes and underwater explosions using neural networks. Bulletin of the Seismological Society of America, v. 93, pp. 215-223.

Dysart, P.S and Pulli, J.J., 1990, Regional seismic event classification at the NORESS array: seismological measurement and the used of trained neural 
network. Bulletin of the Seismological Society of America, v. 80, pp. 1910-1933

Dowla, F.U., Taylor, S.R. and Anderson, R.W., 1990, Seismic discrimination with artificial neural networks: preliminary results with regional spectral data. Bulletin of the Seismological Society of America, v. 80, pp.13461373

Fawcett, T., 2003, ROC Graphs: Notes and Practical Considerations for Data Mining Researchers. Palo Alto, CA, Technical Report HPL-2003-4, Hewlett Packard.

Gitterman, Y., Pinsky, V. and Shapira, A., 1998, Spectral classification methods in monitoring small local events by the Israel seismic network. Journal of Seismology, v. 2, pp, 237-256.

Havskov, J. and Ottemoller, L., 2005, SEISAN Earthquake Analysis Software for Windows, Solaris, Linux and Mac OSX, Version 8.1, http://www.geo ciencias.unam.mx/ gomez/Curso_sismo/manual_seisan_8.1.pdf.

Hamdan., H., 2013, An Exploration of the Adaptive Neuro-Fuzzy Inference System (ANFIS) in Modelling Survival, Thesis submitted to The University of Nottingham for the Degree of Doctor of Philosophy, School of Computer Science, The University of Nottingham, United Kingdom.

Jang, R., 1992, Self-learning fuzzy controllers based on temporal backpropagation. IEEE Transactions, Neural Networks, v. 3 (5), pp. 714 723.

Jang, R., 1993, ANFIS: adaptive-network-based fuzzy inference system. IEEE Transactions, Systems, Man and Cybernetics, v. 23 (3), pp. 665-685.

Jang, R. and Sun, C., 1995, Neuro-fuzzy modeling and control. Proceedings of the IEEE, v. 83 (3), pp. 378-406.

Jenkins, R.D. and Sereno, T. S., 2001. Calibration of regional S/P amplituderatio discriminants. Pure and Applied Geophysics, v. 158, pp. 12791300 .

Joswig, M., 1995. Automated classification of local earthquake data in the BUG small array. Geophysical Journal International, v. 120, pp. 262286.

Lee, K. C. and Oh, S.B., 1996, An intelligent approach to time series identification by a neural network-driven decision tree classifier. Decision Support Systems, v. 17, pp. 183-197.

Muller., S. Garda., P. Muller., J.D. and Cansi., Y., 1999, Seismic events discrimination by neuro-fuzzy merging of signal and catalogue features. Physics and Chemistry of the Earth, Part A: Solid Earth and Geodesy, v. 24A (3), pp. 201-206.

Musil, M., Plesinger, A., 1996, Discrimination between local microearthquakes and quarry blast by multi-layer perceptrons and Kohonen maps. Bulletin of the Seismological Society of America, v. 80, pp. 077-1090.

Nauck, D., 1997, Neuro-fuzzy systems: Review and prospects. In Fifth European Congress on Intelligent Techniques and Soft Computing (EUFIT97), pp. 1044-1053.

Peng, H., Long., F. and Ding., C., 2005, Feature selection based on mutual information: criteria of max- dependency, max relevance and minredundancy. IEEE Transactions, Pattern Analysis and Machine Intelligence, v. 27 (8), pp.1226-1238.
Siva Prasad., M.V. Suresh Kumar., C.H. and Maneesha., T., 2014, Feature selection using an effective dimensionality reduction technique. International Journal of Computer Science and Mobile Computing, v. 3, pp. 480-485.

Scarpetta, S., Giudicepietro, F., Ezin, E. C., Petrosino, S., DelPezzo, E., Martini, M. and Marinaro, M., 2005, Automatic classification of seismic signals at Mt. Vesuvius Volcano, Italy, using neural networks. Bulletin of the Seismological Society of America, v. 95, pp. 185-196. doi:10.1785/ 0120030075.

Sewell, M., 2007, Feature selection. Available online: http://machinelearning.martinsewell.com/feature-selection/feature-selection.pdf (accessed on 21 March 2011).

Tchalenko., J.S, Braud., B.J. and Berberian., M., 1974, Discovery of three earthquake faults in Iran. Nature, v. 248, pp. 661-663.

Tiira, T., 1996, Discrimination of nuclear explosions and earthquakes from teleseismic distances with a local network of short period seismic stations using artificial neural networks. Physics of the Earth and Planetary Interiors, v. 97, pp. 247-268.

Tiira, T., 1999, Detecting teleseismic events using artificial neural networks. Computers and Geosciences, v. 25, pp. 929-939.

Ursino, A., Langer, H., Scarfì, L., Di Grazia, G. and Gresta, S., 2001, Discrimination of quarry blasts from tectonic earthquakes in the Hyblean platform (southeastern Sicily). Annals of Geophysics, v. 44, pp. 703722.

Vieira, J., Morgado Dias, F. and Mota, A., 2004, Neuro-fuzzy systems: A survey, 5th WSEAS NNA International Conference on Neural Networks and Applications, Udine, Italia.

Vasheghani-Farahani., J. and Zaré, M., 2011, The southeastern Tehran earthquake of 17 October $2009(\mathrm{Mw}=4.0)$. Seismological Research Letters, v. 82 (3), pp. 404-412.

Vasheghani-Farahani., J. Zaré, M., and Lucas., C., 2012, Adaptive neurofuzzy inference systems for semi-automatic discrimination between seismic events: a study in Tehran region. Journal of Seismology, v. 16 (2), pp. 291-303.

Vasheghani-Farahani., J. and Zaré, M., 2014, Site characterizations for the Tehran network in Tehran Region Using Micro-Earthquake, Microtremor and Quarry Blast Data. Soil Dynamics and Earthquake Engineering Journal; v. 63, pp. 235-247.

Walter, W.R. and Hartse, H.E., 2013, Monitoring the Comprehensive NuclearTest-Ban Treaty: Seismic Event Discrimination and Identification. Springer-Publisher.

Wang J, and Teng, T.L., 1995, Artificial neural network-based seismic detector. Bulletin of the Seismological Society of America, v. 85, pp. 308-319.

Yildirim, E., Gulbag., A., Horasan., G. and Dogan., E., 2011, Discrimination of quarry blasts and earthquakes in the vicinity of Istanbul using soft computing techniques. Computers \& Geosciences, v. 37, pp. 1209-1217.

Yildirim, E. and Horasan, G., 2008. Discrimination of earthquake and quarry blast data using artificial neural networks. In: Proceedings of the18th International Geophysical Congress and Exhibition, Ankara, Turkey, pp. $1-4$.

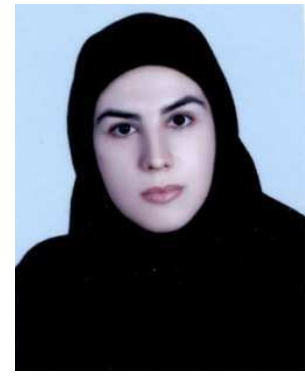

Jamileh Vasheghani Farahani is $\mathrm{PhD}$ of geophysics/engineering seismology in Institute of Geophysics, University of Tehran. Her research domain is focused on strong ground motion and engineering/explosion seismology. Her interest is discrimination between seismic events using nonlinear pattern recognition techniques and spectral methods. Moreover, she is interested in the ray path by estimating the geometrical coefficient and the frequency-dependent quality factor and, non-parametric approach to a ground motion prediction problem for blast and earthquake data. She is working on modern observational seismology. 